\title{
BOLCHEM, an integrated system for atmospheric dynamics and composition
}

\author{
A. Maurizi, M. D'Isidoro and M. Mircea \\ \{Institute of Atmospheric Sciences and Climate\} \\ Correspondence to: A. Maurizi (a.maurizi@isac.cnr.it)
}

\begin{abstract}
The on-line modelling system BOLCHEM consists of a meteorological limited area hydrostatic model (BOLAM) coupled with different gas chemistry models (SAPRC90 and CB-IV chemical mechanisms), an aerosol model (M7, work in progress) and a Lagrangian dispersion model for computation of forward and backward trajectories. The model is under development but recent applications have shown its reliability for air quality studies. Future developments will focus on data assimilation of atmospheric composition and on feedback effects of composition on radiation and dynamics.
\end{abstract}

\section{Introduction}

Chemical composition at regional scale is the subject of increasing interest for both air quality and climatological issues. Several models exist but no on-line Italian model was available some years ago. Different expertise are present at ISAC-CNR on several aspect involved in air-quality modelling: atmospheric chemistry, meteorology, microphysics and turbulence, and these were gathered to develop BOLCHEM. The model is part of the European comunity project GEMS,

sub-project Regional Air Quality models (RAQ) and has been used to study different aspects of air quality related problems.

\section{Model description}

The BOLCHEM model (BOLam + CHEMistry) is the result of an on-line coupling between the mesoscale meteorological model BOLAM (BOlogna Limited Area Model, 
http://www.isac.cnr.it/ dinamica/bolam/index.html) (Buzzi et al., 1994, Buzzi et al., 2003) and modules for transport and transformation of chemical species. BOLAM dynamics is based on hydrostatic primitive equations, with wind components, potential temperature, specific humidity, surface pressure, as dependent variables. The vertical coordinate system is hybrid-terrain-following, with variables distributed on a non-uniformly spaced staggered Lorenz grid. The horizontal discretisation uses geographical coordinates on an Arakawa Cgrid. The time scheme is split-explicit, forward-backward for gravity modes. A 3-d WAF (Weighted Average Flux) advection scheme coupled with semi-Lagrangian advection of hydrometeors is implemented. A fourth order horizontal diffusion of the prognostic variables (except for Ps), a second order divergence diffusion and damping of the external gravity mode are included. The lateral boundary conditions are imposed using a relaxation scheme that minimises wave energy reflection. The initial and lateral boundary conditions are supplied from the ECMWF (European Centre for Medium-range Weather Forecasts) analyses available at $0.5^{\circ} \times 0.5^{\circ}$ resolution. Hybrid model level data are directly interpolated on the BOLAM grid.

Transport (advection and diffusion) of tracers (both passive and reactive) is performed on-line at each meteorological time-step using WAF scheme for advection and a "true" (second order) diffusion, with diffusion coefficient carefully estimated from experiments (Tampieri and Maurizi, "submitted"). Vertical diffusion is performed using one-dimensional diffusion equation with a diffusion coefficient estimated by means of an E-1 turbulence closure scheme. Dry deposition is computed through resistance-analogy scheme and is provided as boundary condition to the vertical diffusion equation. Furthermore, vertical redistribution of tracers due to moist convection is parameterised consistently with the Kain-Frisch scheme used in the meteorological part for moist convection. Transport of chemical species is performed in mass units while gas chemistry is computed in ppm.

Physical/chemical processes are treated separately for gas phase, aerosol classes and generic tracers (e.g. radioactive species, Saharan dust, ... ). Gas phase is treated using the SAPRC90 or CB4 chemical mechanisms. Aerosol is modelled using M7 module from ECHAM5 (coupling still in progress) and generic species are defined by the user case by case providing chemical/physical properties and equations. More technical details can be found in the COST 728/732 model inventory:

http://www.mi.uni-hamburg.de/List_classification_and_detail_view_of_model_entr.567.0.html?\&user_cost728_pi2[showUid]=80 


\section{Model applications}

The model has been used for a variety of situations in order to test the reliability of the choices made. It also currently runs at ECMWF in the frame of GEMS Project for the ensemble near-real-time experiment. Some of the main results are briefly reported in the following sections.

\subsection{Evaluation of model performances for}

\section{2 ozone}

The performances of BOLCHEM on the ability to predict $\mathrm{O} 3$ concentration over Italy were evaluated. The comparison between computed and measured concentrations for some periods of 1999 shown that the model is able to predict the diurnal cycle of O3, in particular in summer. The agreement between modeled and measured quantities is good during the day while at night there is some problem connected to O3 destruction. However, US-EPA's criteria are met so that model results can reliably used for air quality predictions. Some time series of O3 computed with CBIV and SAPRC90 mechanisms are compared to measurements in Figure 1.

\subsection{Ozone sensitivity to precursor emission reduction}

An important aspect for emission reduction policies, is the study of the regional sensitivity to precursor emission reduction. For this purpose indicator species are computed to asses reduction in NOx and VOC over the whole Italy and on subdomains centered on specific spots: the Milan and Rome adeas and some of the major industrial areas. Different periods were selected and runs with both chemical schemes were performed over Italy comparing indicator species computed for different reduction scenarios. For all the periods investigated, it is found that Italy, including the big islands Sicily and Sardinia, is mostly dominated by NOx chemical regimes, independently of the photochemical mechanism used. However, the effect of the reduction of NOx predicted with the CB-IV mechanism is lower than that predicted with SAPRC90 mechanism. In addition, the urban areas around cities as Milan, Rome, Naples or industrialised areas around harbours as Genoa, Messina, Venice are always in a marked VOC sensitive regime. It can be also noted that the differences in the spatial distribution of the chemical regimes due to the photochemical mechanism used and due to the meteorological conditions are comparable. Example of maps of sensitivity of ozone to reduction of VOC and NOx are reported in Figure 2. 


\subsection{Saharan dust transport}

Saharan dust is a major component of the aerosol load over Italy due to the vicinity to the African continent. The direct forcing of dust aerosol may be comparable to or even exceed the forcing of anthropogenic aerosols. To correctly treat this aspect, a proper modelling of surces is needed. A sensitivity experiment was carried out to test the sensitivity of the emission model (Tegen eta al, 2002) to the friction velocity treshold during a strong Saharan dust outbreak that occurred from 15 to 19 July 2003, transporting the dust particle almost over the whole Italy (Figure 3). The comparison of model results with the observations (surface concentrations from EMEP stations and aerosol optical depth (AOD) from AERONET stations) allowed to select the better treshold.

\subsection{Lagrangian transport and Etna eruption}

A Lagrangian transport model is implemented in BOLCHEM (BOLTRAJ variant) that can be used in conjunction with the Eulerian part. This is useful as an analysis tool for a better interpretation of Eulerian simulations through the computation of the probability matrices of pollutant origin. It is also useful to study specif events of concentrated sources when the resolution of the Eulerian grid would be too small to represent dispersion at short time. The first application was the Mt. Etna eruption on Autumn 2002 (Villani et al., 2006). The joint analysis of Lagrangian trajectories, satallite data, meteorology and lidar measurements allowed to estimate the tropospheric dispersion coefficient and to clarify some features observed by lidar located at Potenza. Lidar measurements recorded a strong signal with clear sulphate signature, along with weaker layers above. Satellite images gave no clear evidence but trajectory analysis revealed the nature of the complex picture: part of the trajectories passing over Potenza took a long tour through the sahara region, possibly carrying some silicate and passing over Potenza at the same time (and at different heights) of those coming directly from Mt. Etna (Figure 4).

\section{Acknowledgements}

The authors would like to thank Francesco Tampieri and Sandro Fuzzi for their support. BOLCHEM is developed thanks to GEMS EC Project, ACCENT EC Project, the Italian MIUR project

"AEROCLOUDS", and was also supported by the Italian Ministry of Environment 
through the Program Italy-USA Cooperation on Science and Technology of

Climate Change.

\section{References}

M. D'Isidoro, A. Maurizi, F. Tampieri, A. Tiesi, M. G. Villani. 2005. Assessment of the numerical diffusion effect in the advection of passive tracer in BOLCHEM. Il Nuovo Cimento C, 28, 151-158 (on-line version http://dx.doi.org/10.1393/ncc/i2005-10188-y)

A. Tiesi, M. G. Villani, M. D'Isidoro, A. J. Prata, A. Maurizi, F. Tampieri, 2006. Estimation of dispersion coefficient in the troposphere from satellite images of volcanic plumes. Atmospheric Environment, 40, 628-638 (doi:10.1016/j.atmosenv.2005.09.079).

M. G. Villani, L. Mona, A. Maurizi, G. Pappalardo, A. Tiesi, M. Pandolfi, M. D'Isidoro, V. Cuomo, F. Tampieri. 2006. Transport of volcanic aerosol in the troposphere: the case study of the 2002 Etna plume. J. Geophys. Res., 111, D21102, doi:10.1029/2006JD00712

A. Tiesi, F. Tampieri, A. Maurizi, S. Davolio, M. D'Isidoro, M.G. Villani, L. Mona, G. Pappala rdo, V. Cuomo. 2004. Transport of volcanic aerosol in the troposphere: the case study of the 2002 Etna plume. Atti di 22th Int. Laser Radar Conference, Matera 2004, ESA, pag. 687-690.

Tampieri, F., M. D'Isidoro, A. Maurizi, M. G. Villani and A. Tiesi: "Simulazione e previsione della composizione della troposfera: problemi, modellistica numerica ed un esempio". Nov. 24 - 25 2004. Milano (I). CAPI'04 Workshop.

F. Tampieri, M. D'Isidoro, M. Mircea, M.G. Villani, S. Finardi, C. Silibello, G. Zanini, La composizione dell'atmosfera in Val Padana: qualita dell'aria come problema regionale, 2005, Accademia dei Lincei, 6 giugno 2005.

M. D'Isidoro, S. Fuzzi, A. Maurizi, F. Monforti, M. Mircea, F. Tampieri, G. Zanini, and M.G. Villani, 2005, Development and Preliminary Results of a Limited Area AtmosphereChemistry Model: BOLCHEM, First ACCENT Symposium, Urbino 12-16 September 2005.

M.G. Villani, P. D'Aulerio, M. D'Isidoro, A. Buzzi, F. Fierli, A. Maurizi, M. Mircea, and F. Tampieri, 2005, Model Simulations of the Ozone Concentrations over Europe During the Summer 2003 Heat Wave, First ACCENT Symposium, Urbino 12-16 Settembre 2005.

Tampieri F., M. D'Isidoro, A. Maurizi, A. Tiesi, M. G. Villani, V. Cuomo, L. Mona, G. Pappalardo, N. Spinelli, X. Wang, V.Rizi, D. Balis, T. Trickl, V. Mitev, and G. Kolarov, 2005, Tropospheric transport of volcanic aerosol in the Mediterranean area: a case study based on the 2002 Etna eruption. European Geophysical Union, General Assembly 2005, Wien 24-29 April 2005.

Villani M.G., M. D'Isidoro, A. Maurizi, F. Tampieri. 2006. Osservazioni sul coefficiente di dispersione in atmosfera. Relazione su invito, XCII Congr. nazionale SIF, Torino, 18-23 sett. 2006, Volume dei sommari, pag.143.

M. Mircea, M. D'Isidoro, A. Maurizi, M.G. Villani, A. Buzzi, S. Fuzzi, F. Tampieri, G. Zanini, F. Monforti, L. Vitali. 2006. Ozone modelling over Italy: a sensitivity analysis to precursors using BOLCHEM air quality model. IXX GLOREAM workshop, 11-13 Oct. 2006, Paris

Mihaela Mircea, Massimo D'Isidoro, Maria Gabriella Villani, Alberto Maurizi, Francesco Tampieri, Maria Cristina Facchini, Stefano Decesari, Lorenza Emblico, Sandro Fuzzi, Andrea 
Buzzi , 2006 . Spotlight on the development of the regional air quality model BOLCHEM: adding aerosol model M7, 2o Convengno Nazionale sul Particolato Atmosferico, 10-13 settembre 2006, Firenze.

Buzzi, A., M. Fantini, P. Malguzzi and F. Nerozzi, 1994: Validation of a limited area model in cases of Mediterranean cyclogenesis: surface fields and precipitation scores. Meteorol. Atmos. Phys., 53, 137-153.

Gyakum, J.R., M. Carrera, D.-L. Zhang, S. Miller, J. Caveen, R. Benoit, T. Black, A. Buzzi, C. Chouinard, M. Fantini, C. Folloni, J.J. Katzfei, Y.-H. Kuo, F. Lalaurette, S. Low-Nam, J. Mailhot, P. Malguzzi, J.M. McGregor, M. Nakamura, G. Tripoli and C. Wilson., 1996: A regional model intercomparison using a case of explosive oceanic cyclogenesis. Wea. Forecasting, 11, 521-543.

Buzzi, A., N. Tartaglione and P. Malguzzi, 1998: Numerical simulations of the 1994 Piedmont flood: Role of orography and moist processes. Mon. Wea. Rev., 126, 2369-2383.

Malguzzi, P., and N. Tartaglione, 1999: An economical second order advection scheme for explicit numerical weather prediction. Quart. J. Roy. Met. Soc., 125, 2291-2303.

Buzzi, A., and L. Foschini, 2000: Mesoscale meteorological features associated with heavy precipitation in the southern Alpine region. Meteorol. Atmos. Phys., 72, 131-146

Nagata, M., L. Leslie, H. Kamahori, R. Nomura, H. Mino, Y. Kurihara, E. Rogers, R. L. Elsberry, B. K. Basu, A. Buzzi, J. Calvo, M. Desgagne, M. D'Isidoro, S.-Y. Hong, J. Katzfey, D. Majewski, P. Malguzzi, J. McGregor, A. Murata, J. Nachamkin, M. Roch, C. Wilson, 2001: A Mesoscale Model Intercomparison: A Case of Explosive Development of a Tropical Cyclone (COMPARE III). J. Meteorol. Soc. Japan, 79, 999-1033.

Buzzi, A., M. D'Isidoro, S. Davolio, 2003: A case study of an orographic cyclone south of the Alps during the MAP SOP. Quart. J. Roy. Meteor. Soc. 129, 1795-1818.

Lagouvardos, K., V. Kotroni, A. Koussis, C. Feidas, A. Buzzi, P. Malguzzi, 2003: The meteorological model BOLAM at the National Observatory of Athens: Assessment of twoyear operational use. J. Appl. Meteor., 42, 1667-1678.

Corazza, M., A. Buzzi, D. Sacchetti, E. Trovatore, C. F. Ratto, 2003: Simulating extreme precipitation with a mesoscale forecast model. Meteorol. Atmos. Phys., 83, 131-143.

Tegen, I., Harrison, S.P., Kohfeld, K, Colin Prentice, I, Coe, M., Heinmann,M., 2002, J.Geophys.Res., 107, D21, doi: 10.1029/2001JD000963. 

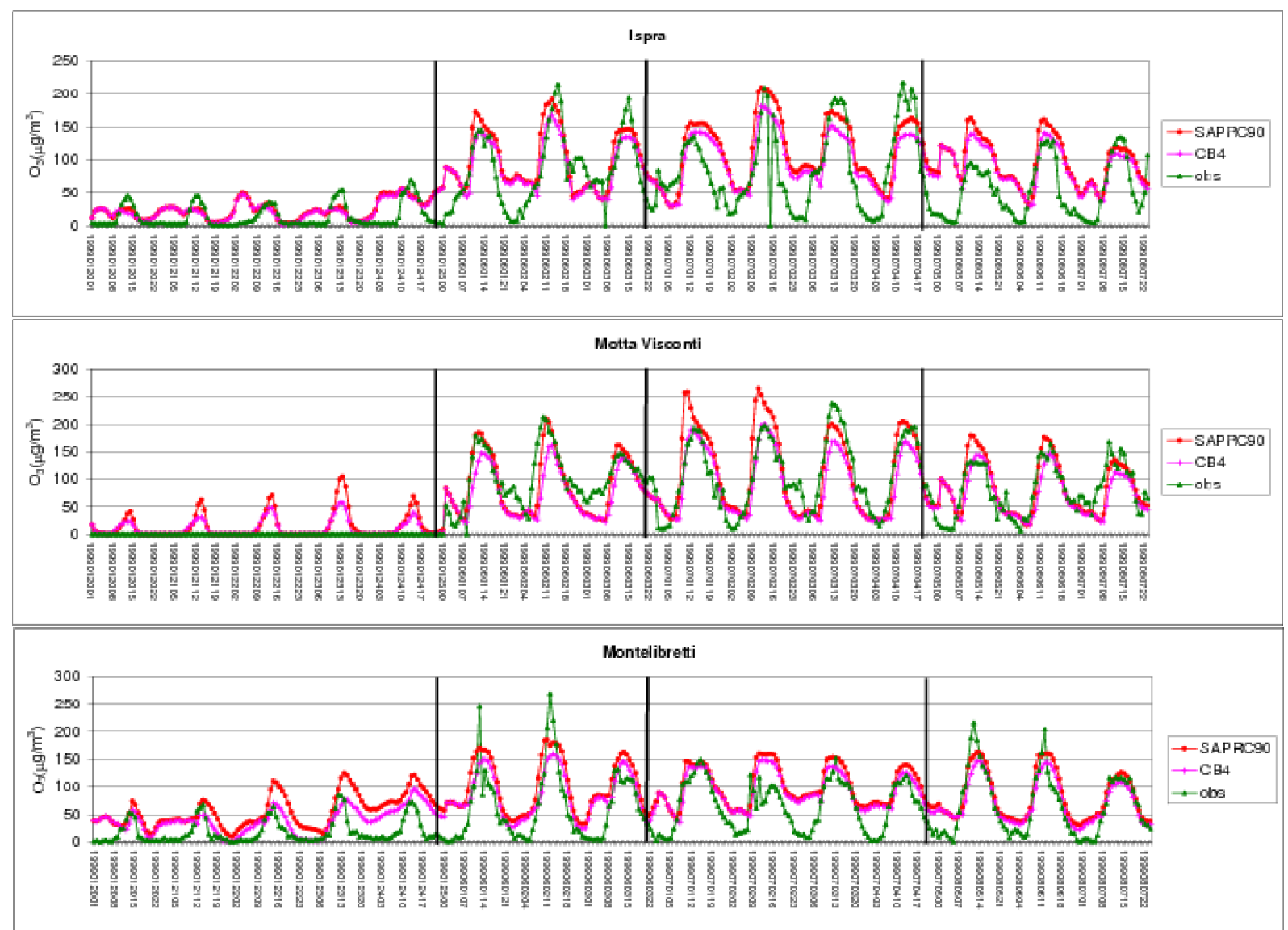

Figure 1. Time series for $\mathrm{O} 3$ in three locations in Italy: Ispra, Motta Visconti (MI) and Montelibretti (RM) for four periods: January, June, July and August. 

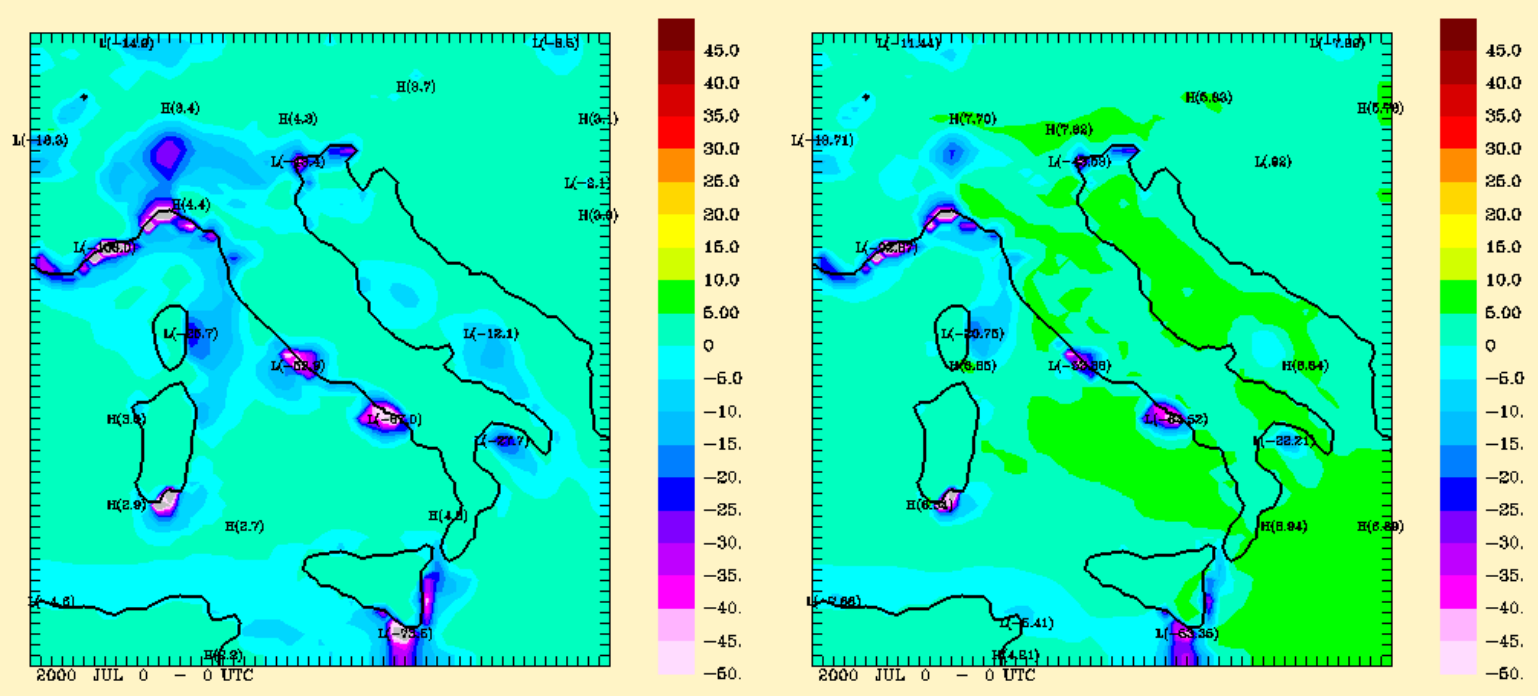

Figure 2. Maps of sensitivity of ozone to reduction of VOC (positive) and NOx (negative). 

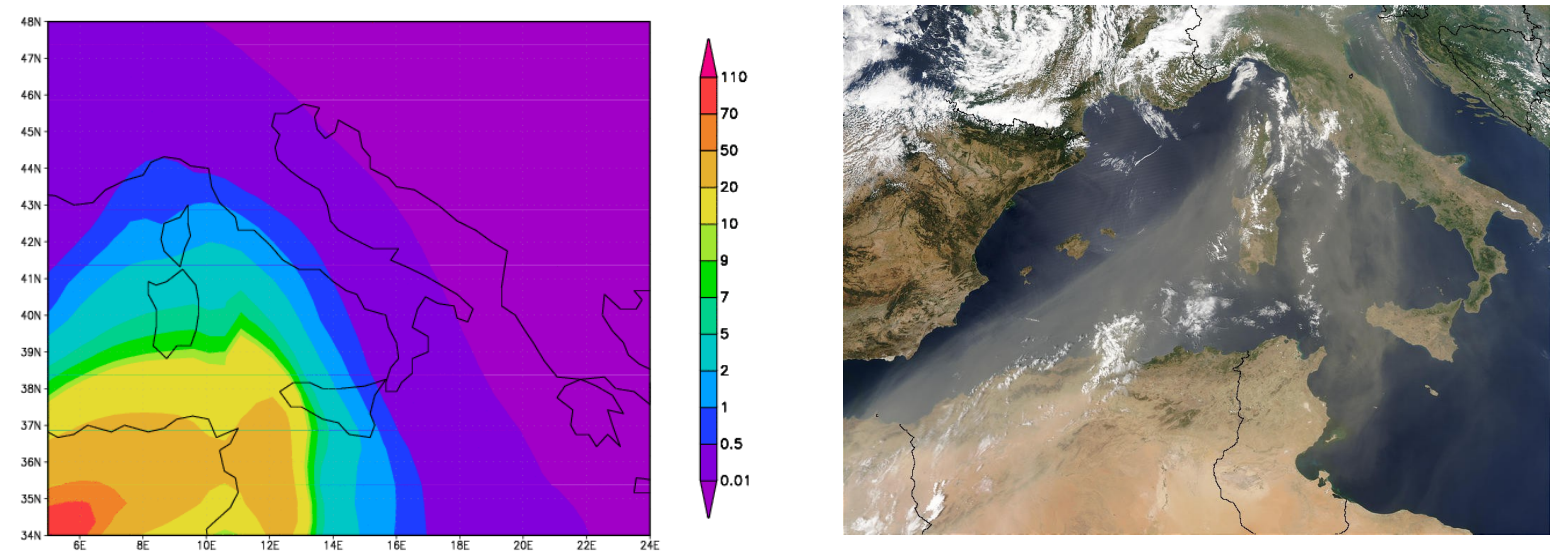

Figure 3. Verticaly integrated aerosol load simulated with BOLCHEM (left) and seen by MODIS AQUA (right). 

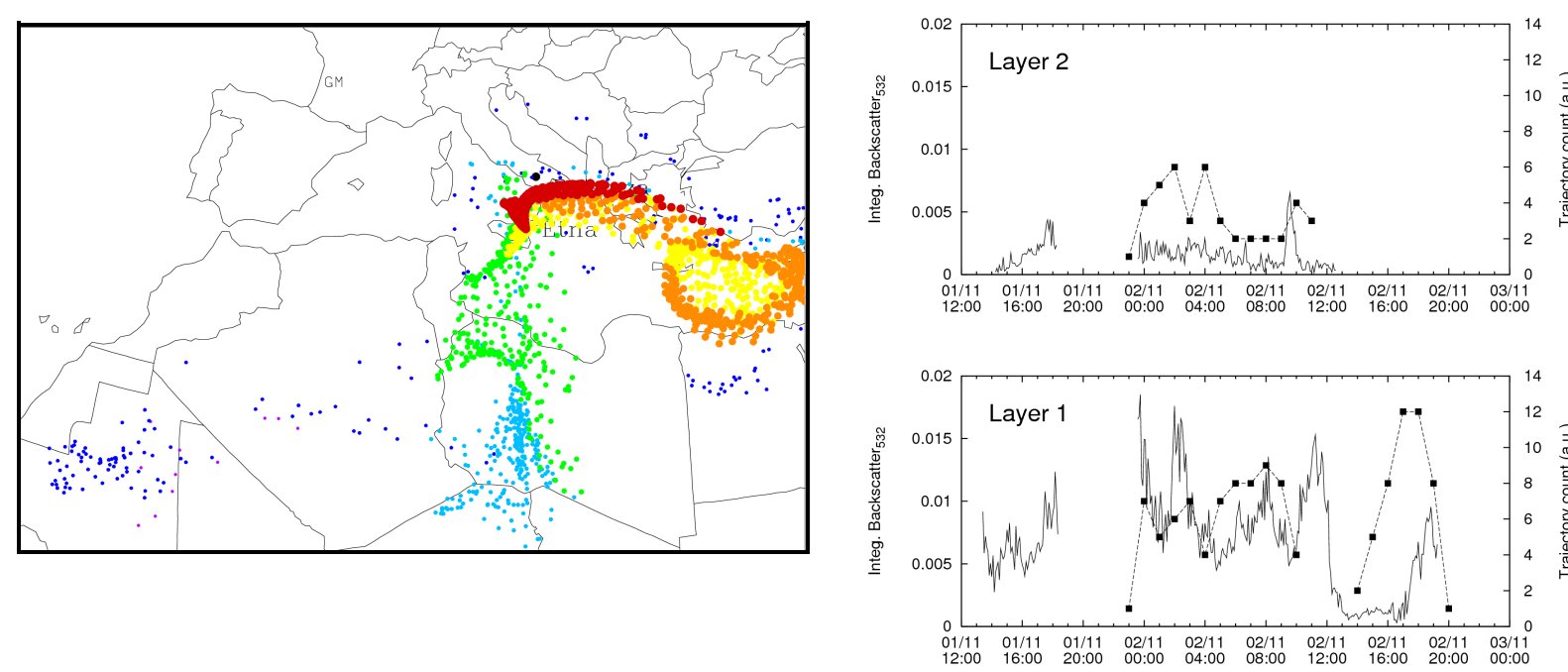

Figure 4. Left panel: position of particles released at Mt. Etna from 26-10-2002 to 01-11-2002. Different colours denote different ages (in days). Right panel: comparison of LIDAR signal measured over Potenza and simulated by BOLCHEM. 